Texas A\&M University-San Antonio

Digital Commons @ Texas A\&M University- San Antonio

\title{
Law Enforcement and Military Members: Engaging in the Community
}

Karen C. Kalmbach

Texas A\&M University-San Antonio, KC.Kalmbach@tamusa.edu

Randy Garner

Sam Houston State University

Follow this and additional works at: https://digitalcommons.tamusa.edu/psyc_faculty

Part of the Psychology Commons

\section{Repository Citation}

Kalmbach, Karen C. and Garner, Randy, "Law Enforcement and Military Members: Engaging in the Community" (2015). Psychology Faculty Publications. 14.

https://digitalcommons.tamusa.edu/psyc_faculty/14

This Article is brought to you for free and open access by the College of Arts and Sciences at Digital Commons @ Texas A\&M University- San Antonio. It has been accepted for inclusion in Psychology Faculty Publications by an authorized administrator of Digital Commons @ Texas A\&M University- San Antonio. For more information, please contact deirdre.mcdonald@tamusa.edu. 


\title{
Law Enforcement and Military Members: Engaging in the Community
}

\author{
Karen C. Kalmbach \\ Texas A\&M University-San Antonio \\ Randy Garner
}

Sam Houston State University

Correspondence concerning this article should be addressed to Karen C. Kalmbach, Ph.D., Department of Psychology, Texas A\&M University-San Antonio, One University Way, San Antonio, TX 78224. Email: Karen.Kalmbach@tamusa.tamus.edu 


\section{MILITARY MEMBERS IN THE COMMUNITY}

Two things happened in the summer of 2012 that crystallized a nation's long-standing concern about military members in the community. ${ }^{1}$ In July, the Pentagon released a report acknowledging military suicide rates had increased significantly and were continuing to climb. Every major news outlet reported military suicides had officially surpassed those of the civilian population; more service members had taken their own lives than were killed in combat in Iraq and Afghanistan combined. Then, in August, Army veteran Wade Michael Page walked into a Wisconsin temple parking lot and shot dead seven congregants as they prepared for morning services. Most Americans had access to these news stories within minutes; frequent updates posted daily. Media coverage of the temple shooting was so immediate, law enforcement was forced to beg helicopter news crews not to broadcast images until the scene was secured. Military suicide and "violent veterans" quickly became the most popular topics on blogs, television and radio, dominating news cycles for the next two weeks. The public was treated to a mixture of facts, political rhetoric, outraged grief and editorializing — conflated to produce an alarming profile of military members in the community.

These stories perfectly highlighted two extreme stereotypes of service members (especially combat veterans): unpredictably violent or emotionally unstable. "[T]he soldier," some have noted, 'is being framed contemporarily, first as a 'criminal,' then as 'victim' (McGarry \& Walklate, 2011, pg. 900). The reality, of course, is that the vast majority of U.S. military members are neither. Bombarded daily with sensational news reports, the public,

\footnotetext{
${ }^{1}$ The U.S. Armed Forces during wartime comprises five branches: Army, Navy, Air Force, Marine Corps and Coast Guard. For simplicity, the terms military member or service member is used herein to include all the foregoing categories of individuals who are now or have ever been in any branch of the military. A distinction is made, when necessary, between a) active duty, b) deployed, c) combat-deployed, d) reserve, e) conscripted vs. all volunteer force (AVF), and f) veterans of current or former wars.
} 
including law enforcement, is poorly informed about the real challenges of service members returning home, and the relative risk posed to the community.

How does such media coverage impact fear of violence and crime? More to the pointhave reported events changed how law enforcement evaluate and respond to a call if a veteran or service member is involved? Putting aside sensational news stories about statistically rare events, what do we know_empirically_about the relationship between military service and mental health problems or violence?

Military culture is highly unifying and unique, yet members can differ widely in important ways (e.g., branch of service, era and length of service, deployment history, combat experience, and military occupational specialty [MOS]) (see Strom et al., 2012). With tens of thousands of service members returning to communities across the nation, the importance of providing accurate information to the public cannot be overstated. Particularly critical is the role of law enforcement; no other entity has such a broad mandate and so few resources. Police are indeed the 'street corner' psychologists, social workers, protectors and mediators - daily filling a role unlike any other in society.

This chapter seeks to assist law enforcement by providing an empirical review of research on the relationship between military service and risk of dangerousness - to self (suicide) or others (violent crime). Risk posed by military members is poorly understood and largely overstated by media reports. The following discussion will reveal that - notwithstanding the unique aspects of military culture and service — most risk factors for violence (towards self and others) are similar for both military members and nonmilitary alike. However, some aspects of military service, (e.g., combat exposure), may impact the behavior and thought processes of service members who come into contact with law enforcement in the community. A better 
informed approach to the issues can assist officers in handling incidents, resulting in safer and more effective outcomes for all involved.

\section{Military Members Returning Home}

After exiting a highly structured and unique institution and lifestyle, veterans must successfully reintegrate back into their communities. Most, but not all, are successful. National estimates suggest that veterans comprise between $26-40 \%$ of the homeless population, despite making up only 7\% of the current U.S. demographic (Copeland et al., 2009; Martinez \& Bingham, 2011; National Law Center on Homelessness and Poverty, 2007). Mental health problems are a chronic concern and rates of some disorders in the military are three to four times that of the civilian population (Hoge et al., 2004; Tanielian \& Jaycox, 2008). Homelessness, mental illness and incarceration are strongly correlated in populations served by the U.S. Department of Veterans Affairs [VA]. These conditions often result from other factors such as lack of access to treatment, medication noncompliance, substance abuse and employment instability (Copeland et al., 2009; Erickson, Rosenheck, Trestman, Ford \& Desai, 2008; MacLean \& Elder, 2007; Pandiani, Ochs, \& Pomerantz, 2010; Siegal, Li, \& Rapp, 2002).

Many service members struggle to find gainful employment, sometimes facing the same unspoken fear and prejudice from potential employers that they often face in the community. ${ }^{2}$ As might be expected, the presence of mental illness can greatly increase risk of unemployment and related financial problems (Elbogen, Johnson, Wagner, Newton \& Beckham, 2012). PostVietnam era veterans have had higher unemployment rates on average than that of nonveterans, despite many government initiatives designed to promote the hiring of veterans. Recently, younger veterans appear to fare the worst (Humensky, Jordan, Stroupe \& Hynes, 2012). In June

\footnotetext{
${ }^{2}$ See for example, http://www.usatoday.com/story/news/nation/2013/04/06/recent-war-vets-face-hiring-obstacleptsd-bias/2057857/
} 
2012, for example, unemployment among 18-24 year old service members was reportedly as high as 30\% (Rieckhoff, 2012). The importance of stable housing and employment is highlighted by a recent national study. Outcome data revealed that employment, stable living circumstances, having enough money to cover basic expenses, social support, and the perception of having control over one's life significantly reduced risk of violence towards others in a veteran sample (Elbogen, Johnson, Wagner et al., 2012).

I was pretty lucky. He could have arrested me. I was pretty belligerent, obnoxious....my friend told me later. I don't remember much about it to be honest. I was drunk, had been drinking all day. Unemployed for over a year. And then her idiot nephew starts setting off firecrackers right behind me. Like it was funny or something. Kid's lucky he runs fast. But that cop, you know, he sat down on the curb beside me. He knew. He'd been over there too. All I remember him saying was 'You need to pull it together man, get some help. You need to fix this.' He was right. A.J.

A legacy of trauma. Some have suggested that the violent and traumatic experiences of war produce troubled individuals, uniquely dangerous to their own communities upon return (see Bucher, 2011; Hayes, 2012; Holowka et al., 2012). Is this a valid general assumption? It is the case that some military members will return home with mental health problems. What is often overlooked however is the fact that some went into the military with problems. Research reveals a significant number of military recruits come from troubled and abusive backgrounds (see Benda, Rodell \& Rodell, 2003; Patrick, Critchfield, Vaccaro, \& Campbell, 2011). For example, a large scale study conducted by the Walter Reed Army Institute of Research found half of all soldiers surveyed reported physical abuse as children. A history of sexual abuse was reported by half of the female soldiers and one-sixth of the male soldiers. Thirty-four percent of female soldiers and $11 \%$ of male soldiers reported a pre-service history of multiple forms of abuse (Rosen \& Martin, 1996). A history of early abuse has been long associated with later mental 
health and behavioral problems. Further, recent research has revealed that female veterans are three to four times more likely to become homeless and are victimized at higher rates than nonveteran females (Washington et al., 2010); both of these factors are known to increase risk of acting out aggressively (increasing the likelihood of coming into contact with law enforcement). Additionally, some veterans may be struggling with the legacy of sexual trauma that occurred while in the military (Ellison, 2011; Kimerling et al., 2010). Recent government data reflects disturbing numbers of female (and male) service members reporting sexual assault in service. ${ }^{3} \mathrm{~A}$ history of abuse or maltreatment is just one factor that has been consistently linked to later criminal justice system involvement as well as mental health problems.

There's about a dozen of us heading to the gate. My friend and me, we're joking about the night before, how it was just like when we were in high school-we all had got messed up on some Hennessey the VIPs had flown in. And he just drops. He crumples like his legs lost power or something. I'm confused, I reach down for him-It's all happening so fast. I swing around, and this $f^{* *}$ er has his rifle up under the chin of my Captain. This guy he had been walking beside, a National, puts his AK right here and pulls the $f^{* * i n g}$ trigger. My boy's down and now my Captain's helmet blows back, his face is... I can see inside his head.... but he's still standing. Then he starts to fall. It's like slow motion, everything is happening so fast, but it's in slow motion. And everybody is shouting and pulling their weapons and pointing at each other and nobody knows who to shoot-these are the guys we spent four months training, eating with, living with.... And I'm staring at him, this ANA guy, and I swear to God he smiles, and he looks just like my old man used to look after he'd beat the crap out of us, and this rage comes over me, hot, and the last thing I remember I'm running at him, screaming, firing, and I can feel his bullets as they go past my face.... Been deployed five times now.... Everywhere, anywhere, anytime. When you least expect it. You better be ready for it, if you plan to stay alive. Like that shooting in Colorado. If I'd have been there, I'd have taken him out. No doubt. S**t like that don't need to live. $\sim S C$

\footnotetext{
${ }^{3}$ See for example http://www.csmonitor.com/USA/Military/2012/0119/Pentagon-report-Sexual-assault-in-themilitary-up-dramatically as well as Department of Defense, Sexual Assault Prevention and Response Annual Report 2011-2012 at http://www.defense.gov/news/sexualassaultannualreportfactsheet.pdf
} 
The wounds of war. The Rand Corporation has drawn attention to the "invisible wounds of war" in a study on the prevalence of posttraumatic stress disorder (PTSD), traumatic brain injury (TBI), and depression, in troops who served during Operation Enduring Freedom [OEF; Afghanistan] and Operation Iraqi Freedom [OIF] (Tanielian \& Jaycox, 2008).

Government data reflects increasing rates of these three diagnoses over a decade of mission eras (OEF/OIF and Operation New Dawn [OND]). Both PTSD and TBI diagnoses show a spike in 2007 (Fischer, 2010), interestingly, paralleling suicide rates (US Armed Forces, 2010). Anxiety disorders and substance abuse are also known to be elevated in combat-exposed military members (Wright, Carter \& Cullen, 2005).

Since 2001, more than 2 million U.S. troops have been called into the service of ongoing wars (Exec. Order No. 13625, 2012). Additionally, in a recent nation-wide study of OIF/OEF/OND veterans, $27 \%$ reported more than one deployment (Elbogen, Johnson, Newton, et al., 2012). ${ }^{4}$ The current all volunteer force (AVF) faces a new and different kind of warfare. For those who have deployed to war zones, unlike any prior conflict, the pace, number, and duration of deployments is much greater than ever before. Operations involve smaller forces in combat theaters that are unconventional, unpredictable, and intense. The Centers for Disease Control and Prevention (CDC) and other agencies have devoted considerable resources to the rapid up-training of medical professionals, most of whom had no prior experience with the type of injuries sustained in OEF/OIF/OND (CDC, n.d.). Repeated exposure to improvised explosive devices (IEDs) and other high order explosives has resulted in multisystem polytrauma injuries seldom seen outside of combat and which challenge the very reach of modern medicine and

\footnotetext{
${ }^{4}$ Of the total active duty military population, typically less than two-thirds (60\%) ever deploy; $40 \%$ are never deployed, and not all deployed service members are deployed to combat zones (Defense Business Board, 2010).
} 
clinical knowledge. Nonetheless, due in great part to medical and technological advances, current casualty rates are much lower than those of any prior prolonged conflict (Fischer, 2010).

But surviving combat may be only half the battle. Some service members return home with invisible injuries - psychological and cognitive trauma not immediately apparent to others. The Rand Corp found much higher rates of major depressive disorders (14\%) and PTSD (14\%) in a veteran survey when compared to community rates; almost half (47\%) had never sought treatment. Approximately one in five (19\%) veterans reported experiencing TBI; more than half (57\%) had never been evaluated for the condition by a physician. In 2008, these rates translated into more than 300,000 veterans with serious mental health or cognitive problems - fully half of which went undiagnosed and untreated. The picture is even worse for service members who have deployed numerous times - one third were reported to have at least one disorder, and one in 20 reported all three (PTSD, depression, and TBI) (Tanielian \& Jaycox, 2008). Other research suggests rates of PTSD may be double those of survey data (i.e., closer to 30\%) when multiple deployments and delayed-onset symptoms are considered (Atkinson, Guetz \& Wein, 2009).

\section{Understanding Risk Factors}

Researchers and mental health professionals refer to risk factors (or risk predictors) when calculating the likelihood of an event happening (e.g., suicide, violence). Risk is a dynamic probability estimate, subject to change across time and situation (see Monahan, 1996). A risk factor, present or absent in an individual's life, does not definitively determine an outcome. Rather, it is simply a factor that has been found to be reliably associated (or correlated) with certain outcomes more times than not. Some risk factors attain strong predictive power only when combined with another (e.g., serious mental illness with substance abuse; see Monahan \& Arnold, 1996). Others, such as a history of violence, are consistently powerful predictors on their 
own. Indeed, past behavior alone may be the single best predictor of future behavior (see Elbogen et al., 2010; Monahan, 1996; Mossman, 1994). However, not all persons with a history of violence or suicide attempts will be violent or suicidal in the future; they simply have $a$ greater likelihood of being so, compared to others with no such history.

Not all risk factors are equally powerful (or useful). Some predictors are weak or indirect, and others are only useful when combined with a number of risk factors in a multivariate group model. However, in general, the more risk factors an individual possesses (relative to protective factors), the greater the likelihood of adverse outcomes. Responding to any call, law enforcement must be able to accurately judge the situation and appropriately assess for risk factors that may be present. A better understanding of empirically validated risk factors will assist officers in making this critical determination.

Evaluating risk - avoiding pitfalls. For law enforcement tasked with responding to real-time threat — often in the absence of any quality information—reliance upon heuristics is imperative. Heuristics are mental short-cuts, or rules, that are employed instead of inspecting every new situation and evaluating it on its own merits. This latter approach would simply take too long. Instead, we wisely learn rules: If the back door is ajar upon arriving home we assume an unauthorized entrance. Heuristics may be thought of as rules that operate largely in our unconscious but are sometimes attributed to "intuition" or "gut instinct." For law enforcement, the use of heuristics may sometimes be the difference between life and death. But can such mental shortcuts ever backfire? Can the unconscious operation of heuristics be detrimental?

When citizens watch a sensational news story about violent crime, without realizing it, many come to believe their own risk of being victimized is suddenly higher than before (or more than crime statistics would predict) (Gilliam \& Iyengar, 2000). Modern media has increased our 
instant access to, and awareness of, the wider world. Yet some events require background knowledge and a larger context to place the event within. Without this larger frame, events can be perceived as more dangerous, more frequent, or more pervasive than they actually are. In the early 1970s, two researchers noted an unconscious strategy that individuals employ when asked to make predictions about the likelihood or probability of an event occurring. In simple terms, we are more likely to overestimate how frequent an event is, if we can easily bring to mind memories of similar events (i.e., if such memories are more "available"). This is especially true for events that are dramatic, frightening, or in some way out of the ordinary. Events that are remembered more easily are believed to be more common, and accurate, than they actually are. This phenomenon was called the availability heuristic (Tversky \& Kahneman, 1973).

The news stories reported at the beginning of this chapter are the kind that will live in the public mind for a long time and perhaps rightly so. The August shooting in Wisconsin was the fourth mass shooting incident of 2012 - the public was rightly concerned (Lynch, 2012). However, very few, if any, reports placed these events within the larger statistical context. To do so would lessen the dramatic impact of the news story. Reports of crime and violence increase newscasts' ratings. The problem, of course, is that the same violent stories the public craves simultaneously increases their fear of violence and convinces them crime is far more prevalent and imminent than it is in reality (Gilliam \& Iyengar, 2000). This is a phenomenon of which law enforcement is intuitively aware. Scholars have used it to explain why Americans persist in believing crime rates are high or increasing, despite data showing violent crime steadily dropping 
for four decades (FBI, 2011; Romer, Jamieson, \& Aday, 2003). ${ }^{5}$ Can professionals also be subject to the same biased thinking? The research would suggest so.

The vast majority of our 23 million military members are neither violent nor suicidal. Military members return home, reunite with family, struggle to reintegrate, find work or go to school, and pay taxes like their neighbors. But these everyday stories are not reported-a nonevent is not a reportable event. However, without the larger context, and based on nothing more than sensational news reports of statistically rare events, the public will be primed to fear military members as potential "time bombs" just waiting to "go off."

Although such violent and tragic incidents are rare, the viewing public does not have the larger context in mind when recalling the stories they have seen in the news. Nor do most citizens pause to calculate the odds of one act of violence relative to the total number of law abiding and peaceful military members across the nation. Additionally, because news stories typically settle quickly on one background factor - military service — the public is often not aware that many other (weightier) risk factors existed in the life histories of many offenders. Law enforcement, whose encounters with military members might be in less than ideal circumstances, may be likewise primed to think immediately of military members as higher risk or more dangerous than they actually are. This perception may unduly influence the handling of incidents involving military members. In some cases military members may pose a greater threat than a nonmilitary community member; however, in the large majority of cases, research suggests they are not more dangerous.

\section{Risk Factors for Violence, Arrest, and Incarceration}

\footnotetext{
${ }^{5}$ Cultivation Theory suggests that prime time and news programming depicts a world far more dangerous and violent than reality would support. Mass consumption of this material produces citizens who are more afraid and who believe their risk of victimization is far greater than the data would suggest.
} 
General population risk factors. A considerable amount of violence risk research of increasing sophistication and scientific rigor has been conducted over the past four decades. Some studies have focused on correctional or psychiatric populations while others include only community members. Results suggest that many risk factors are shared in common: history of prior arrest/violence/criminality, substance abuse, history of childhood abuse (physical and/or sexual), deviant/criminal/incarcerated caregivers (especially drug using fathers), unemployment or employment instability, lower socioeconomic status, living in a high crime neighborhood, psychopathy, antisocial traits, young age at first offense/arrest, early maladjustment, high levels of anger/impulsivity/hostility and prior community supervision failure (See Table 1). Interestingly, serious mental illness alone (e.g., major depression, schizophrenia, bipolar disorder) - long considered to be a risk factor in itself — is actually sometimes found to be negatively correlated with violence, or elevated only when comorbid with substance abuse or an angry/irritable/delusional presentation. In general, simply having a mental illness does not increase one's risk of violence significantly; however, when combined with substance abuse, risk of violence can increase considerably (Benda, Rodell \& Rodell, 2003; Douglas, Cox, \& Webster, 1999; Monahan, 2002; Monahan \& Arnold, 1996).

Risk factors unique to military populations. Exposure to combat and wartime atrocities has been associated with increased threat sensitivity, hypervigilance (Anaki, Brezniak \& Shalom, 2012), marital and family problems (Gimbel \& Booth, 1994), aggression, PTSD symptoms (Beckham, Feldman, \& Kirby, 1998), and risk of violent offending (see Bouffard, 2005; MacLean \& Elder, 2007; White, Mulvey, Fox \& Choate, 2012). Three possible links are explored in the literature: any military service and violence; combat exposure and violence; and mental illness and violence. The research is equivocal; no one factor emerges strongly. However, 
one relatively consistent finding over three decades seems to be a small but significant relationship between combat exposure and increased risk of violence in some military members (MacLean \& Elder, 2007).

Current research shows higher rates of certain mental disorders (notably depression, PTSD, TBI) and related problems (e.g., substance abuse) in the military when compared to the general population (Hoge et al., 2004; Tanielian \& Jaycox, 2008). Some studies have found these mental disorders, in turn, to be associated with increased intimate partner violence, general aggression, poor health, and interpersonal problems (Fontana \& Rosenheck, 2005; Freeman \& Roca, 2001; Rabenhorst et al., 2012; Taft et al., 2005). However, other research has found that risk of incarceration and interpersonal violence is better predicted by antisocial personality disorder (present prior to service), than by PTSD (Shaw, Churchill, Noyes, \& Loeffelholz, 1987; Taft et al., 2012). Research with psychiatric patients found that it was the co-occurrence of substance abuse with a major mental disorder that significantly increased risk of violence (Monahan, 2002), and this finding was confirmed in a recent large-scale study of veterans with PTSD (Elbogen, 2012).

The mischaracterization of PTSD in the media. Although research does exist linking PTSD with a slightly increased risk of violence (see Byrne \& Riggs, 1996), it is not consistently found to be a primary risk factor. Many other risk factors often demonstrate a far more robust relationship with violence (e.g., history of violence, prior arrests, history of physical abuse, substance abuse, psychopathy and antisocial traits) (see Monahan, 2002; Steadman et al., 2000). Nonetheless, much public concern centers on the condition of PTSD and the presumed tendency of those diagnosed with PTSD to 'act out.' 
The defining core of PTSD is the experiencing of extreme trauma which is subsequently re-experienced psychologically and/or physiologically, with symptoms of persistent hyperarousal, and avoidance of recollection of the trauma (APA, 2000, p. 468). These features have been frequently misinterpreted and distorted by the media. For example, "One of the symptoms of PTSD," a Huffington Post blogger writes, "is uncontrollable violence” (Benedict, 2009). Unfortunately, this statement is both factually incorrect and grossly irresponsible. Nowhere in the definition of PTSD is a criterion of "uncontrollable violence." Presumably the blogger is referring to one of 19 possible symptoms, namely, "irritability or outbursts of anger." This particular criterion is neither required for a diagnosis of PTSD nor universally experienced by individuals with PTSD. Equating irritability or outbursts of anger with "uncontrollable violence" is just one way PTSD is mischaracterized in the media, adding to the public's confusion and fear. The vast majority of individuals diagnosed with PTSD, whether military members or not, are neither violent nor unstable (see Appendix A for discussion).

A recent national study revealed that it was only when PTSD presented with high levels of anger/irritability, or, was comorbid with substance abuse, that risk was significantly elevated (Elbogen, 2012). Researchers hypothesized that veterans with PTSD who also report high levels of anger/irritability would have higher arrest rates than other veterans. This hypothesis was confirmed in simple bivariate analyses. However, when all risk factors were statistically entered into the analysis, overall probability of arrest was linked more strongly to substance abuse and criminal history than to PTSD or other mental illness. Interestingly, authors discovered that, contrary to prior research, it was not combat exposure, nor PTSD or TBI alone that best predicted arrests. Instead, researchers found some of the same risk factors as in nonmilitary populations including prior arrest history, younger age, male gender, alcohol/drug abuse, history 
of family violence, and recent homelessness (see Elbogen, 2012; Elbogen \& Johnson, 2009;

Elbogen, Johnson, \& Newton et al., 2012; Skeem, Manchak \& Peterson, 2011).

These and other findings suggest that military service (particularly combat exposure) and related mental health problems may play a role in the increased risk of violence, arrest, and/or incarceration for a small minority of veterans. However, results also highlight the fact that most risk factors for most individuals are the same for both veterans and nonveterans alike.

Digging deeper: A case in point. On a beautiful Sunday morning in August, Oak Creek Police Department in Wisconsin received an active shooter call. An unidentified male had launched an assault on a group of Sikh worshipers as they assembled for morning services. Ultimately, 40 year old Wade Michael Page would take several bullets to the torso from officers before raising his own weapon and discharging it into his head, ending the siege which would ultimately leave seven dead and others wounded (Nelson, 2012). By afternoon, the FBI assumed jurisdiction; news updates began featuring the term domestic terrorism (CNN Wire Staff, Aug 5, 2012). Within 12 hours, the shooter had been identified as an Army veteran (Associated Press, Aug 6, 2012). Tensions ran high. Just two weeks earlier the nation had reeled under the news of a lone shooter calmly opening fire on an audience in a darkened theater in Colorado, ultimately killing 12 and wounding 58. Many wondered aloud, on blogs and in interviews, whether he might be a veteran. He was not. Unfortunately for the family, his grandfather was a veteran, and the Contra Costa Times was quick to report this fact as though it were somehow relevant (Hennessey, 2012).

When a perpetrator is found to be a military member, this fact dominates. Many important questions related to other more important risk factors are not asked, and these critical details are often presented secondarily if at all. However, utilizing nothing but news reports, it 
becomes quickly apparent that a host of other common, and far more powerful risk factors for violence, are often present in the backgrounds of offenders who happen to be military members. According to The Army Times ${ }^{6}$ and many other news reports, Page served for six years, was never deployed to combat (although he is said to have told 'war stories' to neighbors), and was demoted and discharged from the Army following a 'pattern of misconduct' including substance abuse and being absent without leave (AWOL). Additionally, Page had criminal histories in at least two states (and possibly four) ${ }^{7}$ primarily for impaired driving. He did not complete his mandatory drug treatment sentence in Colorado. A charge for impaired driving in North Carolina was dropped in $2010,{ }^{8}$ but he was fired from at least one job for operating a truck while impaired, ${ }^{9}$ and is reported to have been frequently unemployed due to heavy drinking. ${ }^{10}$ Page was also reported to have undergone recent property foreclosure, had a troubled relationship with a convicted felon, ${ }^{11}$ and lost his mother at an early age. Perhaps most importantly, we now know that he was long affiliated with neo-Nazi hate groups. According to many interviews Page gave to Dr. Peter Simi, ${ }^{12}$ (a 'hate rock' music researcher at the University of Nebraska), Page began to endorse increasingly racist ideology after exposed to the diversity he encountered in the military (CNN, August 7, 2012).

\footnotetext{
${ }^{6}$ See http://www.armytimes.com/news/2012/08/ap-sikh-temple-shooting-army-veteran-080612/

${ }^{7}$ See http://video.msnbc.msn.com/nightly-news/48539422\#48539422

${ }^{8}$ See http://latino.foxnews.com/latino/news/2012/08/07/sihk-temple-shooter-michael-wade-urged-fellow-whitesupremacist-to-get-involved/

${ }^{9}$ See http://www.businesswire.com/news/home/20120806006418/en/Barr-Nunn-Issues-Statement-Wade-MichaelPage

${ }^{10}$ See http://www.huffingtonpost.com/brian-levin-jd/exclusive-interview-with_b_1751181.html

${ }^{11}$ See http://abcnews.go.com/US/wisconsin-gunman-wade-michael-pages-girlfriend-arrested/story?id=16954183

${ }^{12}$ See http://www.huffingtonpost.com/brian-levin-jd/exclusive-interview-with_b_1751181.html
} 
Table 1. Risk Factors for Violence, Arrest, Incarceration

General Population

- Past history of violence or arrests

- Substance use/abuse

- Younger age/young age at first arrest

- Male gender

- Lower socioeconomic status (SES)

- Lower education level

- History of childhood maltreatment/abuse

- History of witnessing domestic violence

- Psychopathy/Antisocial traits

- Parental criminality (esp. father's drug use)

- High Anger/Hostility/Suspiciousness

- $\quad$ Major mental illness * (with substance abuse)

- Unemployment and/or Employment Instability

* Major mental illness not found consistently to elevate risk; in some cases the inverse was found. Substance abuse in combination with major mental illness reliably increases risk of violence

** Not consistently found across studies

Compiled Sources: Douglas, Cox, \& Webster, 1999; Elbogen et al., 2010; Elbogen, Johnson, Newton et al., 2012; Otto \& Douglas, 2009; Steadman et al., 2000.

In the information found in news reports alone, Page's history reveals a handful of the most powerful predictors of violence and criminal offending — none of which are related to military service. Despite these clearly delineated and well known risk factors for violence—news reports continued to highlight Page's veteran status. Similarly, when individuals with military experience take their own lives, news reports will often note veteran status first, before 
identifying other relevant risk factors in the deceased's background. In the case of suicide, as with acts of violence towards others, the majority of risk predictors are similar for military and nonmilitary community members alike. However, as the next section will address, based on emerging research, we now know that a few variables uniquely related to military experience appear to elevate risk in some service members (see Ilgen et al., 2012).

\section{Risk Factors for Suicide}

Law enforcement is in the unenviable position of being the only public entity which cannot say 'no' to any call for help. Although not trained in a wide range of social services, they must nonetheless respond to all such emergencies. Currently, many agencies are beginning to implement mandatory mental health training or specialized response teams. Of the myriad of situations an officer can find himself or herself in (from the bizarre to the terrifying), one of the most personally challenging is a potential suicide incident.

In June 2012, a Pentagon report confirmed what many had feared - the overall rate of active duty military suicides had risen to an unprecedented level and was averaging nearly one per day - the greatest number and fastest growing statistic since such data had begun to be collected (Associated Press, June 7, 2012). Confirmed suicides outpaced the number of troops killed in action. "While suicide remains a relatively rare event...it is increasing at an unprecedented rate and, unlike any other time in history, U.S. military suicide rates now appear to have surpassed those among comparable civilian populations. It is therefore critical that we address this emerging public-health problem," warned a doctor who works with veterans (Castillo, 2012).

Approximately 34,000 Americans take their own lives annually (94 per day) in the United States (CDC, 2010). According to VA estimates, 18 veterans commit suicide per day, 
totaling a disproportionate $20 \%$ of all suicides annually (Shinseki, 2010). Adding active duty suicides to this number, it becomes clear why the President himself has called for action issuing an executive order directing the VA to immediately expand suicide prevention programs and improve mental health services (Exec. Order No. 13625, August 2012).

Risk factors in the general population. Experts have identified a number of important risk factors for suicide in the general population (see Pope \& Vasquez, 2011). Historically, the highest rate of suicide in America was for elderly Caucasian males (36 per 100,000 in the 75 years of age and older group), although we are beginning to note disturbing trends in younger and racial/ethnic minority groups (i.e., 31 per 100,000 in 15-34 year old American Indian and Alaskan Natives) (CDC, 2010). Compared to younger Americans, suicide attempts by older individuals tend to be more successful, having been more carefully planned and executed. For many elderly persons, long term or chronic mental health problems such as depression or cognitive decline are suspected to be one important causal factor. Lack of resources and physical illness, in addition to losing loved ones over time, are also thought to contribute to the high risk of this demographic. The top risk factors for suicide in the general population include: a history of suicide attempts, evidence or articulation of a specific suicide plan, and a pervasive sense of hopelessness (often a feature of major depression). Ill health, job loss or financial difficulty, as well as a history of mental illness or psychiatric hospitalization are risk factors that also contribute to suicide in the general population. Substance abuse plays a role, just as it does in the commission of violent acts, by reducing impulse control and long term consequence assessment. Although females attempt suicide more often, males are much more likely to complete the act, typically using more lethal means. Interestingly, some military suicide statistics stand in contrast to this general population suicide profile. 
Risk factors unique to military populations. Historically, military suicide rates have long been lower than that of the general population (Harrell \& Berglass, 2011; White, Barber, Azrael, Mukamal, \& Miller, 2011). Prior to 2007, there were proportionally more suicides in the general population than in the military; beginning in 2007 that pattern reversed. The Army, for example, saw suicides spike in 2004 and rates have continued to climb - from 9 per 100,000 (2001), to more than 24 in 100,000 (2011) (Black, Gallaway, Bell, \& Ritchie, 2011). Any increase in suicide rates is of concern. However, are military suicide rates dramatically higher than comparable civilian populations as widely reported? Or is this yet another example of media-fuelled misinformation?

Problems with military suicide data. Military suicide data is often incomplete and opaque. Not all suicides are captured or identified. Not all branches of service report data or calculate trends in the same manner. Complicating the issue further is the fact that there exists no coordinated reporting process between the Department of Defense (DoD) and the VA (Harrell \& Berglass, 2011). Furthermore, the majority of news reports tend to compare military suicide rates to general population rates with no adjustment or statistical correction for the very different sex and age ratio makeup of the military. Therefore, it is important to note that when adjusted general population rates are used, most branches of the military continue to have rates modestly lower than or comparable to the civilian population with only one exception: the Army (see Figure 1).

Young males: A high risk group. Males - especially young males — are at higher risk for many things, including violent crime, auto accidents, homicide, suicide, and substance abuse (Brooks, 2012; Park, Mulye, Adams, Brindis, \& Irwin, 2006; Snyder, 2011). In the United States, males comprise nearly $50 \%$ the population; however, in the military, $80-95 \%$ of service 
members are male. Young adult males (18-24yrs) make up 10\% of the general U.S. population. Of military members, more than two-thirds (67\%) are under 30 years of age. Specifically, 18-21 year olds comprise $20 \%$ of active duty forces with an additional $47 \%$ aged $22-30$ years. There is variation across branches. Marines are the youngest of all: $37 \%$ are $17-22$ years of age (83\% of troops are younger than 30). The average Marine, in 2011, was a 25 year old Caucasian male (29 in the Army and Navy; 30 in the Air Force and Coast Guard). Caucasians comprised $75 \%$ of active duty troops (Howden \& Meyer, 2011; Defense Manpower Data Center, 2011).

This dramatic difference in sex and age representation between the general population and military is important and become highly relevant when discussing the potential risk posed by military members. Apart from any other factor, a large portion of the military comprise a group with pre-existing qualities that place them in a higher risk group, simply by virtue of being young and male. Indeed, notwithstanding current concerns, given the overrepresentation of selfselected, risk tolerant young males in the military, one might even say it is surprising that the rate of adverse outcomes is not greater.

With respect to suicide, males are four to five times more likely to complete a suicide compared to females (although females attempt more often). In other words, if the general population comprised $80-95 \%$ males (as in the military), general population suicide rates would be much higher than reported. If age and race/ethnicity were factored in, rates might shift again (suicide rates are higher for Caucasians than minority group members). The importance of statistically corrected population estimates is addressed by some (e.g., Bruenig, 2012; United States Armed Forces, 2010) but typically overlooked by most media reports. The difference between demographically corrected general population suicide rates and non-corrected data is significant (see Figure 1). While there is no doubt that military suicide is a serious problem and 
worthy of directed resources, it is equally important to note that current trends have effectively increased the averaged rate to that of the corrected civilian population. Only one branch - the Army-remains above the rate for the general population.

Nonetheless, based on data from the past five years, it is clear that, for at least three branches (Army, Marines, and Air Force), suicides have increased. What factors contribute to these suicide statistics? Does the self-selection of primarily young males who choose to enter the military, especially during wartime, predict something about risk-tolerance or risk-taking behavior? Do the personal histories of service members contain risk factors unknown to official investigators?

Suicide by branch of service and demographic. Suicide rates for the Marine Corps, historically the highest of all branches, more than doubled between 2006 and 2009 before dropping back down in 2010. Army suicides, the largest group in absolute numbers, spiked in 2004 and have climbed relentlessly since that time (Harrell \& Berglass, 2011; Maurer \& Watson, 2010). The Army comprises the majority (38\%) of current active duty military members, and, along with the Marine Corps (14\%), are most likely to be 'boots-on-the-ground' combat weary and bearing the greatest casualties (Fischer, 2010; Office of the Under Secretary of Defense, Personnel and Readiness, 2010; Statistic Brain, 2011). Although Air Force pilots and the Navy's Construction Battalions (Seabees) and Medical Corps also deploy in-country, typically, the Air Force, Navy, and Coast Guard provide supportive functions during wartime. Seemingly consistent with this, the Marine Corps and Army service members have the highest rates of suicide.

However, suicide data can be puzzling. For example, rates for members of the National Guard and Reserve units who have never deployed also increased. This pattern is also true for the 
other branches: In 2009, 52 Marines killed themselves; $31 \%$ (16) had never deployed. In 2007, a similar pattern was noted for the Army; of 115 confirmed suicides, 26\% (30) had never deployed (Center for Deployment Psychology, n.d.). Increases in suicides in Guard and Reserve units may be the result of difficulty adjusting to 'fulltime' military service, but explaining increased rates in the never-deployed is more challenging. The reason has yet to be determined. "'Suicides have increased across the military,' Defense Secretary Leon Panetta told Congress.... 'service members of all branches are killing themselves at the rate of about one per day. That is an epidemic,' he testified. 'Something's wrong"' (Zoroya, 2012). What risk factors are driving the increase in military suicides, and how do they compare to those found in the community?

Statistically, a majority of military members are very young (approximately half are 17 25 years of age), Caucasian (75\%) and male (85\%). This is also the demographic which is currently at highest risk for suicide in the military. However, even before the 2007 spike in suicide rates, between 1993 and 2002, suicide was the first and second leading cause of death for female and male veterans respectively (Center for Deployment Psychology, n.d.; Lutz, 2008; Martin, Ghahramanlou-Holloway, Lou, \& Tucciarone, 2009; Office of the Under Secretary for Defense, Personnel and Readiness, 2010).

Many of the general population risk factors for suicide apply to both military and non military community members alike (Griffith, 2012). However, research has identified factors unique to military service which appear to increase suicide risk. The military risk demographic is much younger although still Caucasian. Recent evidence suggests that it may be military service itself —including frequent deployment, combat trauma/violence, PTSD/TBI, loss of colleagues, stigmatization/avoidance of help seeking, alcohol abuse, and greater firearm availability - that are more proximate predictors of suicide in the military (Barnes, Walter, \& 
Chard, 2012; Black, Gallaway, Bell, \& Ritchie, 2011; Bryan \& Cukrowicz, 2011; Harrell \&

Berglass, 2011; Mansfield, Bender, Hourani, \& Larson , 2011; Martin, Ghahramanlou-Holloway, Lou, \& Tucciarone, 2009).

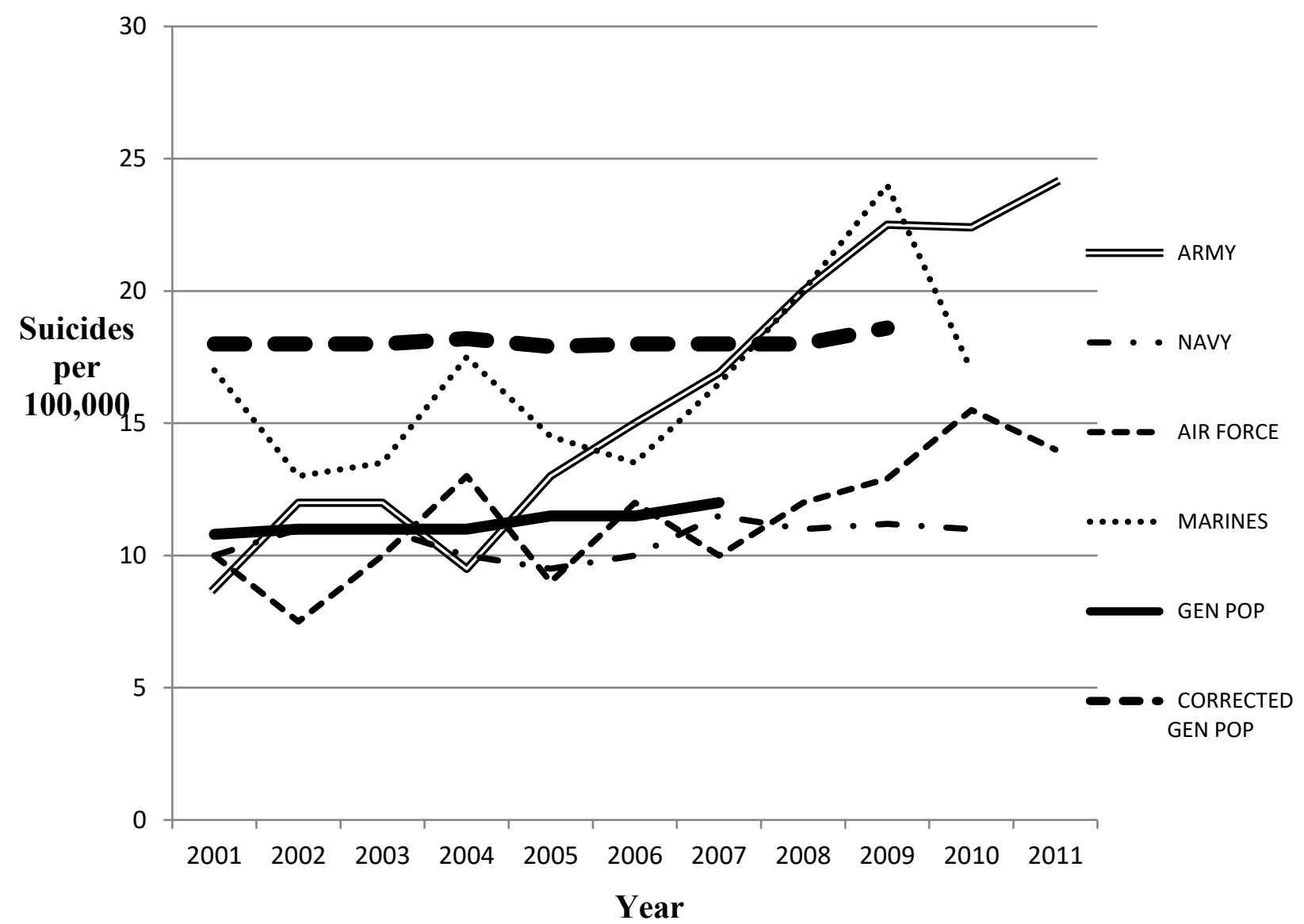

Figure 1. Civilian and Military Suicides by Branch of Service 2001 - 2011.

Source: Reconstructed from multiple print and online data sources including Harrell \& Berglass, 2011; US Armed Forces, 2010; US Census Bureau, 2012.

Suicide in the Army. In 2007, the prototypical Army suicide completer was a young, unmarried, junior, enlisted Caucasian male. At that time, approximately $96 \%$ of military suicides were males and $81 \%$ were active duty; half had a recently failed relationship but the majority had no documented psychiatric history (6\% had a PTSD diagnosis). Approximately $30 \%$ of 
suicides involved drug or alcohol abuse, and the most common method of suicide was a firearm (CDC, 2010; Center for Deployment Psychology, n.d.). In addition to major depression, both PTSD and TBI are known to independently increase risk of suicide; other disorders are often cooccurring for those with a TBI diagnosis (Barnes, Walter \& Chard, 2012).

For law enforcement responding to a potential suicide incident, it is import to know that, for military members, suicide risk factors may be more complex than those of the civilian population. The stressful lifestyles of many service members (deployment, combat, financial issues, separation from loved ones) may exacerbate mental health problems which, absent military stressors, would otherwise be manageable. In some cases, the typical protective factors do not mitigate risk in a military population. For example, in the general population, close relationships such as marriage can be a protective factor; however, marriage has not emerged as a protective factor in the military (possibly because of the stress of distance, frequent relocations, and separation).

Certain jobs or occupations [MOS] within the military may expose service members to greater levels of trauma. For example, combat medics are often tasked with traumatic life-saving duties under severely compromised conditions and with limited supplies; many must deliver life saving care even while in hot zones with no protection for themselves. Mortuary affairs and remains recovery personnel are required to handle dead and disfigured bodies and body parts on a regular basis. Death notification can take a toll on service members even when stateside. Infantry soldiers are often asked to perform a range of duties sometimes far outside their training, in unfamiliar regions and cultures, while taking the brunt of explosive-related trauma and other physical injuries which can result in long term medical conditions or chronic pain and disability (see CDC, n.d.). Military police are often required to serve in dangerous and inhospitable 
regions, sometimes in close supervision of detainees who may pose a chronic, imminent, and dynamic risk of violence towards the military member.

\section{A Dangerous Barrier -- Stigma}

Law enforcement must be mindful of the fact that many military members in the community may have no connections to mental health care providers or hospitals. Indeed, the majority are likely to have no record of mental health care documented while in service. For many service members, a visit to the Chaplain is the only acceptable, non-stigmatized route for seeking help. This avoidance of mental health providers is regrettable; with appropriate, timely and compassionate intervention, even challenging symptoms can be mitigated. However, the greatest obstacle to receiving assistance may be that military culture is not conducive to helpseeking of any kind. Indeed, many military members are reportedly advised that answering 'Yes' to any post-deployment mental health questions will delay them from going home with their unit (a mandated psychiatric evaluation will be triggered). Even less appealing is the reporting of mental health concerns during service or deployment. Even in distress, most service members will avoid visiting mental or behavioral health services for fear of becoming socially ostracized or negatively viewed in terms of career advancement. In fact "concern about stigma was disproportionately greatest among those most in need of help from mental health services" (Hoge et al., 2004).

The prevalence of this widespread stigma virtually ensures minimal incentive exists for military members to answer truthfully when given mental health screens or questionnaires. As a result, many veterans may have no service records indicating the presence of mental health problems. Currently, stigmatization has been characterized by the military as the "biggest 
deterrent to seeking help"; a public commitment to reducing stigma and increasing awareness is now part of the mandate for all branches of service (e.g., U.S. Armed Forces, 2010).

Do you know what it's like to hold a child in your arms that you've run over-on orders? But here she is, four, maybe five years old. Same as my daughter back home. Long brown hair, brown eyes staring up at me. Her legs are missing. Blood everywhere. Sgt is yelling at me to get my ass back in the Humvee, and the father or brother or someone runs towards us-he's screaming and crying, holding his arms out for her, and they open fire on him. Next thing I know, I'm covered in his brains and blood, and his daughter's or sister's blood and the whole family goes insane. Howling, wailing, asking me 'Why? Why did you do this?' It's chaos, and all I can think is that I can't put her down and I can 't keep holding her. It's been four years. I still see her face every night I close my eyes. $\sim$ J.S.

Law enforcement must approach each situation without prejudice, cognizant that situations involving service members vary widely and are impacted by individual circumstances. As a general matter, the vast majority of current and former service members are not dangerous to themselves or others. However, as noted previously, in certain situations, especially if substance abuse or a mental health problem is involved, the officer should attempt to assess for all risk factors including those that may be unique to military service. In the case of suicide, these unique factors may include: violence/combat exposure, repeated deployments, violent loss of comrades/repeated bereavement, stigmatization of help-seeking, greater firearm availability, legal or administrative problems, poor social support network/relationship problems (due to military lifestyle), and mental health problems (substance abuse PTSD, TBI, depression). 
Table 2. Risk Factors for Suicide

General Population

Unique to Military

- History of suicide attempts

- Specific plan; lethal means

- Statement of intent

- Mental illness/history of hospitalization

- Depression/hopelessness

- Substance abuse (esp. alcohol)

- Multiple stressful events

- Health problems

- Single/Divorced/No children

- Lack of belonging (social/family)

- Bereavement/Loss of loved one

- Unemployment

- Older age (75yrs+)

- Male/Caucasian
- Frequent/extended deployment/stoploss

- Violent bereavement/loss of colleagues

- Combat intensity/violence exposure

- Greater firearm availability

- PTSD; TBI; depression *

- Alcohol abuse

- Stigmatization/avoidance of helpseeking

- Chronic pain/injury

- Poor social support/relationship problems $* *$

- Legal problems

- Disciplinary/performance problems

- Medical/administrative discharge

- Younger age

- Male/Caucasian

\footnotetext{
* Although mental illness, including PTSD, is a risk factor for suicide, the majority had no documented psychiatric history or diagnosis (only 6\% had a formal PTSD diagnosis)

* Marriage does not appear to be a protective factor in military populations
}

Sources: Barnes, Walter \& Chard, 2012; Black, Gallaway, Bell, \& Ritchie, 2011; Griffith, 2012; Harrell \& Berglass, 2011; Martin, Ghahramanlou-Holloway, Lou, \& Tucciarone, 2009; Pope \& Vasquez, 2011; U.S. Armed Forces, 2010. 


\section{Engaging Military Members in the Community}

Military culture is unique yet similar to law enforcement culture in many ways. In fact, this similarity may account for the attractiveness of policing as a career for many exiting service members. The rigorous training, intense camaraderie fostered by shared experiences in dangerous situations, and the hierarchical organizational structure is familiar to both law enforcement and military members. Law enforcement officers are encouraged to be aware of and to leverage those similarities to engage effectively with military members, especially in crisis situations. As discussed previously, much research has identified the impact of the "hidden wounds of war." Importantly for law enforcement, this has resulted in an abundance of information suggesting that some service members are returning home with problems which, if left untreated, can result in depression, suicide, substance abuse, or relational problems. In turn, these issues can lead to involvement with law enforcement and the ultimately the criminal justice system.

Responding to the need: Compassion and training. Police agencies are gaining greater awareness of emerging issues when responding to incidents that involve a military member. Many officers themselves know the stress associated with witnessing terrifying or lifethreatening events, death, and traumatic injury. The aftermath of such exposure can have longranging, consequential effects on an officer. Emotional numbing, heightened arousal, sleep disturbance, recurring visualizations or memories, and avoidance may occur (Hoge, Castro, Messer, McGurk, Cotting, \& Koffman, 2004). An officer's typical coping mechanism can be impacted resulting in behavior that is seemingly inconsistent with the situation. This shared experience can be invaluable in developing rapport with military members who may be in crisis. However, law enforcement should not ever presume to understand a military member's 
experience; it is much more effective to garner as much as information as possible from collateral sources and then seek to query the veteran himself or herself. In this way, careful and respectful communication can assist in the development of trust and credibility.

As first responders, police officers and law enforcement professionals are now being better trained and prepared to recognize signs of mental health problems in order to help military members receive needed assistance (Ritchie, 2012; Weaver, Joseph, Dongon, Fairweather, \& Ruzek, 2013). Additionally, given the disturbing suicide data on service members, many agencies are providing officers with resource lists, including referral agencies and crisis hotlines. Several police training and intervention programs have been developed using scenario-based training, role playing, and group discussion to supplement other fact-based or resourced-based information. Such programs also include other emergency services personnel such as dispatchers, paramedics, and firefighters (Etter, McCarthy, \& Asken, 2011). Law enforcement who themselves are veterans, can be invaluable in assisting other department personnel understand and more effectively respond to incidents involving military members in the community.

Law enforcement officers responding to a call involving a military member may encounter an individual who has witnessed events that few others could fathom-except perhaps - a police officer. The training internalized by military personnel involves survival in a combat or hostile environment — not something that is typically encountered in the community, and not a skill set that translates well in the civilian population. In some cases, officers may be asked to intervene with individuals who have been in a near constant state of hypervigilance, have been trained to rely on weapons for defense, and have been taught to respond immediately to imminent or perceived threat. Additionally, issues of social isolation, separation and 
disconnectedness from family or other support abound. Many military members have missed the birth or graduation of a child, wedding anniversaries, or funerals of loved ones back home.

Conversely, some have become all too acquainted with death on the battlefield but cannot talk about it with civilians. Coupled with the stress of returning to a less regimented and structured life while facing the uncertainty of post-service employment, it is easy to see how incidents involving some military members have the potential to become volatile.

Effective incident management. Most law enforcement officers strive to engage all community members with respect and dignity; however, this is particularly important for veterans, who often feel like alienated strangers in their own communities. Although there may not be clear early information about veteran status, when law enforcement arrive and begin speaking with individuals on the scene, that information will often surface. If possible, the dispatcher may inquire about the military status of the individual when taking the initial call and relay that to the responding officers. Depending on the situation, if there exists some reason to believe that a community member might be former military, officers may ask initial questions such as "Have you served in the military?" or "What was your branch of service [or 'MOS' if Army]?” Depending on the response, officers can gain additional information by asking questions related to deployment and length of service. If such questions are not possible, other indications may be present such as the presence of 'dog tag' identification, military tattoos, military style clothing or footwear, and so forth. Additionally, manner of bearing or demeanor as well as speech can help identify those with past military service. Many expressions, for example: 'That's when I got my weapon and I told him to stand down!' can provide clues. The use of military time in the conversation may be an additional indicator (e.g., "I told you I returned home at 1800 hours!"). Awareness is crucial. 
Once it becomes apparent that law enforcement is engaging a person with a military background, content-specific training and heightened sensitivity comes into play. While remaining vigilant about personal and public safety, officers can view the current situation within the context of an individual who may be suffering from an injury. The military member may not be entirely functional or able to understand or optimally control their behavior. For example, in addition to mental health problems, the military member may be suffering from hearing loss (due to repeated blast or gunfire exposure) or other physical injuries that result in chronic pain or mood lability which could affect his or her thinking, judgment and behavior.

If possible, law enforcement will want to help the military member regain a sense of safety and reduce any perceived imminent threat. This is not the time to rush towards resolution or unnecessarily encroach upon personal space. Military members may have been in positions where personal safety, autonomy and control have been repeatedly threatened or violated. It is imperative that law enforcement officers avoid being perceived as similarly threatening. If the situation allows, a slower, supportive, calm and confident tone and demeanor can help to deescalate the situation. Respect is crucial. The military fosters a culture rich in tradition and strong on values such as bravery, loyalty, honor, and strength. If possible, the service member should be treated in a manner that communicates respect and avoids suggesting they are weak or cowardly.

Abrupt or furtive movements should be avoided if possible. A service member's military training might flag these actions as threatening. If an officer is going to reach into a pocket or duty bag, it may be best to first describe this action (i.e., "I'm going to reach into my pocket to get my notebook" or "I'm going to answer the dispatcher to tell them everything is OK."). External stressors such as unnecessary noise: sirens, radio traffic, crying/yelling/arguing of other 
individuals or family members should be minimized. If an officer is attempting to build rapport with an individual, those who might adversely impact the development of that relationship (such as an irritated relative or an upset child) should be directed to another location.

As law enforcement works to establish rapport with the military member, they must remain ever cognizant that, as in any incident, the situation could deteriorate quickly. If the individual begins acting erratically or dangerously, officers must be prepared to respond appropriately in defense of public and personal safety. As always, the ultimate goal is to provide a positive and successful resolution to the problem with minimal harm incurred. If possible, once the immediate situation has been resolved, the military member (or family members) should be referred to appropriate service agencies to receive the kind of care needed to mitigate the likelihood of such events in the future. All responding officers should have readily available a list of local VA hospitals, clinics, emergency rooms or crisis line contacts.

\section{Conclusion}

Following each major foreign conflict, the American public has voiced concern about the danger posed by returning military members (see, for example, Bennett, 1954). Following more than a decade of ongoing wars (OIF/OEF/OND), both civilian and military populations are currently exhausted by the effort and cost. Estimates by the Institute of Medicine (IOM) suggest that the maximum cost load of caring for these veterans will not hit until the year 2040 (IOM; 2010). In the intervening years, the public will need to adjust to the reassimilation of hundreds of thousands of young and middle aged military members. There is no question that military service - especially combat exposure - can impact the mental health and functioning of service members. However, after decades of research, findings consistently indicate the majority of risk 
factors for both suicide and violent offending are primarily the same in both military and nonmilitary populations.

Law enforcement responding to calls involving military members are advised to consider such individuals in a holistic manner and not automatically over-weight the influence of a military history. Military service is but one background factor that may or may not play a role in the behavior of community members. Law enforcement should first familiarize themselves with general risk factors for harm to self and others, as these factors tend to be the weightiest in any assessment regardless of military status. They should next consider the unique aspects of military service which may or may not play a role in any given incident. A well-informed and skillful approach to engaging with military members in the community can improve outcomes and increase the likelihood of a successful incident resolution with no harm occurring to any party. 


\section{References}

American Psychiatric Association [APA]. (2000). Diagnostic and statistical manual of mental disorders (4th ed., text rev.). Washington, DC: Author.

Anaki, D., Brezniak, T., \& Shalom, L. (2012). Faces in the face of death: Effects of exposure to life-threatening events and mortality salience on facial expression recognition in combat and noncombat military veterans. Emotion, 12(4), 860-867.

Associated Press. (2012, June 7). U.S. military averaging a suicide a day in 2012. CBS News. Retrieved from See http://www.cbsnews.com/8301-201_162-57449214/u.s-militaryaveraging-a-suicide-a-day-in-2012/?tag=contentMain;contentBody

Associated Press with Fishel, J., Levine, M., \& Winter, J. (2012, August 06). Gunman in Sikh temple shooting identified as ex-army soldier Wade Michael Page. FOX News. Retrieved from http://www.foxnews.com/us/2012/08/06/authorities-search-for-motive-in-deadlyshooting-at-wisconsin-sikh-temple/

Atkinson, M., Guetz, A., \& Wein, L. (2009). A dynamic model for posttraumatic stress disorder among U.S. troops in Operation Iraqi Freedom. Management Science, 55(9), 1454-1468.

Barnes, S.M., Walter, K.H., \& Chard, K.M. (2012). Does a history of mild traumatic brain injury increase suicide risk in veterans with PTSD? Rehabilitation Psychology, 57(1), 18-26.

Beckham, J.C., Feldman, M.E., \& Kirby, A.C. (1998). Atrocities exposure in Vietnam combat veterans with chronic posttraumatic stress disorder: Relationship to combat exposure, symptom severity, guilt, and interpersonal violence. Journal of Traumatic Stress, 11(4), $777-785$.

Benda, B.B., Rodell, D.E., \& Rodell, L. (2003). Crime among homeless military veterans who abuse substances. Psychiatric Rehabilitation Journal, 26(4), 332-345. 
Benedict, H. (2009, January 14). Violent veterans, the big picture. Huffington Post. Retrieved from http://www.huffingtonpost.com/helen-benedict/violent-veterans-thebig_b_157937.html

Bennett, J.V. (1954). The criminality of veterans. Federal Probation, 18(29), 40-42.

Black, S., Gallaway, M.S., Bell, M.R., \& Ritchie, E.C. (2011). Prevalence and risk factors associated with suicides of Army soldiers 2001-2009. Military Psychology, 23, 433-451.

Bouffard, L. (2005). The military as a bridging environment in criminal careers: Differential outcomes of the military experience. Armed Forces \& Society, 31(2), 273-295

Brooks, R. (2012, September 27). No army for young men. Foreign Policy. Retrieved from http://www.foreignpolicy.com/articles/2012/09/27/no_army_for_young_men?print=yes\& hidecomments=yes $\&$ page $=$ full

Bruenig, M. (2012, June 12). Military suicide rate and the importance of demographic controls. [Web log post]. Retrieved from http://mattbruenig.com/2012/06/12/military-suicide-rateand-the-importance-of-demographic-controls/

Bryan, C.J., \& Cukrowicz, K.C. (2011). Associations between types of combat violence and the acquired capability for suicide. Suicide and Life-Threatening Behavior, 41(2), 126-136.

Bucher, J. (2011). General issue (GI) strain: Applying strain theory to military offending. Deviant Behavior, 32, 846-875.

Byrne, C.A., \& Riggs, D.S. (1996). The cycle of trauma: Relationship aggression in male Vietnam veterans with symptoms of posttraumatic stress disorder. Violence and Victims, 11(3), 213-225. 
Cable News Network [CNN] (2012, August 7). Military, music marked temple suspect's path to Wisconsin. CNN. Retrieved from http://www.cnn.com/2012/08/06/us/wisconsinshooting-suspect/index.html?iid=article_sidebar

Cable News Network (CNN) Wire Staff. (2012, August 5). Gunman, six others dead at Wisconsin Sikh temple. CNN. Retrieved from http://www.cnn.com/2012/08/05/us/wisconsin-temple-shooting/index.html

Castillo, M. (2012, July 10). Study: suicide rates among army soldiers up 80 percent. CBS News. Retrieved from http://www.cbsnews.com/8301-504763_162-57394452-10391704/studysuicide-rates-among-army-soldiers-up-80-percent/

Center for Deployment Psychology. (n.d.). Addressing the Psychological Health of Warriors and Their Families. [Training Manual for Civilian Providers] Training provided in Houston, TX, October 3-7, 2011. Author.

Centers for Disease Control and Prevention (CDC). (n.d.) Explosions and blast injuries: A primer for clinicians. Retrieved September 25, 2012 from http://www.bt.cdc.gov/masscasualties/pdf/explosions-blast-injuries.pdf

Centers for Disease Control and Prevention (CDC). (2010, Summer.) Suicide: Facts at a glance. Retrieved from http://www.cdc.gov/ViolencePrevention/pdf/Suicide_DataSheet-a.pdf

Copeland, L.A., Miller, A.L., Welsh, D.E., McCarthy, J.F., Zeber, J.E., \& Kilbourne, A.M. (2009). Clinical and demographic factors associated with homelessness and incarceration among VA patients with bipolar disorder. American Journal of Public Health, 99(5), $871-877$. 
Defense Business Board. (2010, July 22). Reducing overhead and improving business operations: Initial observations. [Presentation]. Retrieved from http://timemilitary.files.wordpress.com/2012/03/punaro-brf.pdf

Defense Manpower Data Center (2011, Aug 8). Demographics of U.S. Active Duty Military. [Reported by Statistic Brain] Retrieved September 25, 2012 from http://www.statisticbrain.com/demographics-of-active-duty-u-s-military/

Douglas, K., Cox, D., \& Webster, C. (1999). Violence risk assessment: science and practice. Legal and Criminological Psychology, 4(2), 149-184.

Elbogen, E. (2012, April 4). Criminal justice involvement among Iraq and Afghanistan war veterans: Risk factors and barriers to care. [Webinar/ PowerPoint presentation/UNC Chapel Hill]. Available from http://www.google.com/url?sa=t\&rct=j\&q=criminal $\% 20$ justice $\% 20$ involvement $\% 20 \% 20$ among\%0Biraq $\% 20$ and $\% 20$ afghanistan $\% 20$ war\%20veterans $\% 3 \mathrm{~A} \% 20$ risk $\% 20$ factors $\% 2$ 0and $\% 20$ barriers $\% 20$ to $\% 20$ care $\&$ source $=$ web $\& c d=1 \&$ ved=0CCcQFjAA\&url=http $\% 3 \mathrm{~A}$ $\% 2 \mathrm{~F} \% 2 \mathrm{Fwww}$.pacenterofexcellence.pitt.edu\%2Fdocuments $\% 2$ FElbogen $\% 2520 \mathrm{Criminal}$ \%2520Justice\%2520Webinar\%25204\%25202012.pptx\&ei=ki5-

UKyVJsmc2QXeq4Ao\&usg=AFQjCNHswky9nv-REZpAkU26S43MV8GSNw

Elbogen, E., Fuller, S., Johnson, S., Brooks, S., Kinneer, P., Calhoun, P., \& Beckham, J. (2010). Improving risk assessment of violence among military Veterans: An evidence-based approach for clinical decision-making. Clinical Psychology Review, 30, 595-607.

Elbogen, E., \& Johnson S. (2009). The intricate link between violence and mental disorder: Results from the national epidemiologic survey on alcohol and related conditions. Archives of General Psychiatry, 66, 152-161. 
Elbogen, E., Johnson, S., Newton, V., Straits-Troster, K., Vasterling, J., Wagner, H., \& Beckham, J. (2012, October 1). Criminal justice involvement, trauma, and negative affect in Iraq and Afghanistan war era veterans. Journal of Consulting and Clinical Psychology, Advance online publication. DOI: 10.1037/a0029967

Elbogen, E., Johnson, S., Wagner, R., Newton, V., \& Beckham, J. (2012). Financial well-being and postdeployment adjustment among Iraq and Afghanistan war veterans. Military Medicine, 177(6), 669-675.

Ellison, J. (2011, April 3). The military’s secret shame. Newsweek Magazine. Retrieved from http://www.thedailybeast.com/newsweek/2011/04/03/the-military-s-secret-shame.html

Etter, D., McCarthy, L., \& Asken, M. (2011) Police negotiations with war veterans: Seeing through the residual fog of war. FBI Law Enforcement Bulletin, July 2011.

Exec. Order No. 13625 (2012, August 31). Executive Order-Improving access to mental health services for veterans, service members, and military families. Retrieved from http://www.whitehouse.gov/the-press-office/2012/08/31/executive-order-improvingaccess-mental-health-services-veterans-service

Federal Bureau of Investigation [FBI] (2011). Preliminary Annual Uniform Crime Report: January - December 2011. Retrieved from http://www.fbi.gov/about-us/cjis/ucr/crimein-the-u.s/2011/preliminary-annual-ucr-jan-dec-2011

Fischer, Hannah. (2010, September 28). U.S. Military Casualty Statistics: Operation New Dawn, Operation Iraqi Freedom, and Operation Enduring Freedom [RS22452]. Report for Congress. Washington, DC: Congressional Research Service. Retrieved from http://www.fas.org/sgp/crs/natsec/RS22452.pdf 
Fontana, A., \& Rosenheck, R. (2005). The role of war-zone trauma and PTSD in the etiology of antisocial behavior. The Journal of Nervous and Mental Disease, 193(3), 203-209.

Freeman, T.W, \& Roca, V. (2001). Gun use, attitudes toward violence, and aggression among combat veterans with posttraumatic stress disorder. The Journal of Nervous and Mental Disease, 189(5), 317-320.

Gilliam, F., \& Iyengar, S. (2000). Prime suspects: The influence of local television news on the viewing public. American Journal of Political Science, 44(3), 560-573.

Gimbel, C., \& Booth, A. (1994). Why does military combat experience adversely affect marital relations? Journal of Marriage and the Family, 56, 691-703.

Griffith, J. (2012). Suicide in the Army National Guard: An empirical enquiry. Suicide and LifeThreatening Behavior, 42(1), 104-119.

Hayes, A. (2012, January 17). Experts: Vets' PTSD, violence a growing problem. Cable News Network [CNN]. Retrieved from http://articles.cnn.com/2012-01-17/us/us_veteransviolence_1_iraq-war-vet-face-death-penalty-homeless-men?_s=PM:US

Harrell, M., \& Berglass, N. (2011, October). Losing the battle: The challenge of military suicide. [Policy Brief]. Washington, DC: Center for a New American Security. Retrieved from http://www.cnas.org/files/documents/publications/CNAS_LosingTheBattle_HarrellBergl ass.pdf

Hennessey, V. (2012, July 20). James Holmes: accused Colorado shooter is grandson of decorated veteran, has family roots in Monterey County. Contra Costa Times. Retrieved from http://www.contracostatimes.com/rss/ci_21124710? source=rss 
Hoge, C., Castro, C., Messer, S., McGurk, D., Cotting, D., \& Koffman, R. (2004). Combat duty in Iraq and Afghanistan, mental health problems, and barriers to care. The New England Journal of Medicine, 351, 13-22.

Holowka, D.W., Wolf, E.J., Marx, B.P., Foley, K.M., Kaloupek, D.G., \& Keane, T. (2012). Associations among personality, combat exposure and wartime atrocities. Psychology of Violence, 2(3), 260-272.

Howden, L. \& Meyer, J. (2011, May). Age and Sex Composition-2010. 2010 Census Briefs. United States Census Bureau. Retrieved from http://www.census.gov/prod/cen2010/briefs/c2010br-03.pdf

Humensky, J., Jordan, N., Stroupe, K., \& Hynes, D. (2012). How Are Iraq/Afghanistan-Era Veterans Faring in the Labor Market? Armed Forces \& Society, 0095327X12449433, 126. First published online June 19, 2012 as DOI: 10.1177/0095327X12449433

Ilgen, M.A., McCarthy, J.F., Ignacio, R.V., Bohnert, A., Valenstein, M., Blow, F.C., \& Katz, I.R. (2012). Psychopathology, Iraq and Afghanistan service, and suicide among Veterans Health Administration patients. Journal of Consulting and Clinical Psychology, 80(3), 323-330.

Institute of Medicine [IOM]. (2010). Returning home from Iraq and Afghanistan: Preliminary assessment of readjustment needs of veterans, service members, and their families. Washington, DC: The National Academies Press.

Kimerling, R., Street, A., Pavao, J., Smith, M., Cronkite, R., Holmes, T., \& Frayne, S. (2010). Military-related sexual trauma among Veterans Health Administration patients returning from Afghanistan and Iraq. American Journal of Public Health, 100(8), 1409-1412. 
Lutz, A. (2008). Who joins the military?: A look at race, class, and immigration status. Journal of Political and Military Sociology, 36(2), 167-188.

Lynch, R. (2012, August 06). Sikh temple rampage: list of mass shootings grows - and grows. Los Angeles Times. Retrieved from http://articles.latimes.com/2012/aug/06/nation/la-nann-sikh-temple-rampage-20120806

MacLean, A., \& Elder, G. (2007). Military service in the life course. Annual Review of Sociology, 33, 175-196.

Mansfield, A.J., Bender, R.H., Hourani, L.L., \& Larson, G. E. (2011). Suicidal or self-harming ideation in military personnel transitioning to civilian life. Suicide and Life-Threatening Behavior, 41(4), 392-405.

Martin, J., Ghahramanlou-Holloway, M., Lou, K., \& Tucciarone, P. (2009). A comparative review of U.S. military and civilian suicide behavior: Implications for OEF/OIF suicide prevention efforts. Journal of Mental Health Counseling, 31(2), 101-118.

Martinez, L., \& Bingham, A. (2011, November 11). U.S. Veterans: By the numbers. ABC News, Retrieved from http://abcnews.go.com/Politics/us-veterans-numbers/story?id=14928136 \#all

Maurer, K. \& Watson, J. (2010, August 26). Marine's suicide rate highest in the military, report says. My SA. Retrieved from http://www.mysanantonio.com/news/military/article /Marines-suicide-rate-highest-in-the-military-785337.php

McGarry, R., \& Walklate, S. (2011). The soldier as victim: Peering through the looking glass. British Journal of Criminology, 51, 900-917.

Monahan, J. (1996). Violence prediction: The past twenty and the next twenty years. Criminal Justice and Behavior, 23(1), 107-120. 
Monahan, J. (2002). The MacArthur studies of violence risk. Criminal Behavior and Mental Health, 12, S67-S72.

Monahan, J., \& Arnold, J. (1996). Violence by people with mental illness: A consensus statement by advocates and researchers. Psychiatric Rehabilitation Journal, 19(4), 67-70.

Mossman, D. (1994). Assessing predictions of violence: Being accurate about accuracy. Journal of Consulting and Clinical Psychology, 62(4), 783-792.

National Law Center on Homelessness and Poverty (2007). 2007 Annual report: Changing laws, changing lives. Washington, DC: Author. Retrieved from http://www.nlchp.org /content/pubs/2007_Annual_Report2.pdf

Nelson, L. (2012, August 22). Officer critically injured in Sikh temple shooting leaves hospital. Los Angeles Times. Retrieved from http://www.latimes.com/news/nation/nationnow/lana-nn-officer-temple-shooting-leaves-hospital-20120822,0,1363010.story

Office of the Under Secretary of Defense, Personnel and Readiness (2010). Population representation in the military services. Retrieved from http://prhome.defense.gov/RFM/MPP/ACCESSION\%20POLICY/PopRep2010/contents/ contents.html

Otto, R. \& Douglas, K. (Eds.). (2009). Handbook of violence risk assessment tools. Milton Park, UK: Routledge.

Pandiani, J.A., Ochs, W.R., \& Pomerantz, A.S. (2010). Criminal justice involvement of armed forces veterans in two systems of care. Psychiatric Services, 61(8), 835-837.

Park, M., Mulye, T., Adams, S., Brindis, C., \& Irwin, C. (2006) The health status of young adults in the United States. Journal of Adolescent Health, 39, 305-317. 
Patrick, V., Critchfield, E., Vaccaro, T., \& Campbell, J. (2011). The relationship of childhood abuse and early separation from the military among Army advanced individual trainees. Military Medicine, 176(2), 182-185.

Pope, K.S., \& Vasquez, M.J.T. (2011). Recognizing, assessing, and responding to suicidal risk. Ethics in psychotherapy and counseling: A practical guide (4th ed) (pp. 292-314). Hoboken, NJ: John Wiley \& Sons, Inc.

Rabenhorst, M.M., Thomsen, C.J., Milner, J.S, Foster, R.E., Linkh, D.J., \& Copeland, C.W. (2012). Spouse abuse and combat-related deployments in active duty air force couples. Psychology of Violence, 2(3), 273-284.

Rieckhoff, P. (2012, June 22). Solving the riddle of veteran unemployment. Forbes. Retrieved from http://www.forbes.com/sites/paulrieckhoff/2012/06/22/solving-the-riddle-ofveteran-unemployment/

Ritchie, E. (2012). How cops can best deal with vets. Time, Aug. 27, 2012. Retrieved from http://nation.time.com/2012/08/27/how-cops-can-best-deal-with-vets/\#comments

Romer, D., Jamieson, K.H., \& Aday, S. (March, 2003). Television news and the cultivation of fear of crime. Journal of Communication, 88-104.

Rosen, L. \& Martin, L. (1996). The measurement of childhood trauma among male and female soldiers in the U.S. Army. Military Medicine, 161(6), 342-345.

Shaw, D.M., Churchill, C.M., Noyes, R., \& Loeffelholz, P.L. (1987). Criminal behavior and post-traumatic stress disorder in Vietnam veterans. Comprehensive Psychiatry, 28(5), 403-411. 
Shinseki, E. (2010, January, 11). Remarks by Secretary Eric K. Shinseki. Department of DefenseVeterans Affairs. Suicide Prevention Conference. Retrieved from http://www.va.gov/opa/speeches/2010/10_0111hold.asp

Siegal, H.A., Li, L., \& Rapp, R.C. (2002). Case management as a therapeutic enhancement: Impact on post-treatment criminality. Journal of Addictive Diseases, 21(4), 37-46.

Skeem, J., Manchak, S., \& Peterson, J. (2011). Correctional policy for offenders with mental illness: Creating a new paradigm for recidivism reduction. Law and Human Behavior, 35, $110-126$.

Snyder, H. (2011). Arrest in the United States, 1980-2009 [NCJ 234319]. Bureau of Justice Statistics. Retrieved from http://bjs.ojp.usdoj.gov/content/pub/pdf/aus8009.pdf

Statistic Brain. (2011). Demographics of active duty U.S. military. Retrieved from http://www.statisticbrain.com/demographics-of-active-duty-u-s-military/

Steadman, H., Silver, E., Monahan, J., Appelbaum, P., Clark Robbins, P., Mulvey, E., Grisso, T., Roth, L., \& Banks, S. (2000). A Classification Tree Approach to the Development of Actuarial Violence Risk Assessment Tools. Law and Human Behavior, 24(1), 83-100.

Strom, T.Q., Leskela, J., Gavian, M.E., Possis, E., Loughlin, J., Bui, T., Linardatos, E., \& Siegel, W. (2012). Cultural and ethical considerations when working with military personnel and veterans: A primer for VA training programs. Training and Education in Professional Psychology, 6(2), 67-75.

Taft, C.T., Kachaduorian, L.K., Suvak, M.K., Pinto, L.A., Miller, M.M., Knight, J.A., \& Marx, B.P. (2012). Examining impelling and disinhibiting factors for intimate partner violence in veterans. Journal of Family Psychology, 26(2), 285-289. 
Taft, C.T., Pless, A.P., Stalans, L.J., Koenen, K.C., King, L.A., \& King, D.W. (2005). Risk factors for partner violence among a national sample of combat veterans. Journal of Consulting and Clinical Psychology, 73(1), 151-159.

Tanielian, T, \& Jaycox, L.H. (2008). Invisible wounds of war: Psychological and cognitive injuries, their consequences, and services to assist recovery. Santa Monica, CA: Rand Corp. Retrieved from http://www.rand.org/multi/military/veterans.html

Tversky, A., \& Kahneman, D. (1973). Availability: A heuristic for judging frequency and probability. Cognitive Psychology 5(2), 207-232.

United States Armed Forces. (2010). Army Health Promotion, Risk Reduction, Suicide Prevention Report 2010. Retrieved from http://csf.army.mil/downloads/HP-RRSPReport2010.pdf

United States Census Bureau (2012). Table 516. Active duty military deaths by manner of death: 1980-2010. Statistical Abstract of the United States: 2012. Retrieved from http://www.census.gov/compendia/statab/2012/tables/12s0516.pdf

Washington, D.L., Yano, E.M, McGuire, J., Hines, V., Lee, M., \& Gelberg, L. (2010). Risk factors for homelessness among women veterans. Journal of Health Care for the Poor and Underserved, 21 (2010), 81-91.

Weaver, C., Joseph, D., Dongon, S., Fairweather, A., and Ruzek, J. (2013). Enhancing services response to crisis incidents involving veterans: A role for law enforcement and mental health collaboration. Psychological Services, 10(1), 66-72.

White, M.D., Mulvey, P., Fox, A.M., \& Choate, D. (2012). A hero's welcome? Exploring the prevalence and problems of military veterans in the arrestee population. Justice Quarterly, 29(2), 258-286. 
White, R., Barber, C., Azrael, D., Mukamal, K.J., \& Miller, M. (2011). History of military service and the risk of suicidal ideation: Findings from the 2008 National Survey on Drug Use and Health. Suicide and Life-Threatening Behavior, 41(5), 554-561.

Wright, J.P., Carter, D.E., \& Cullen, F.T. (2005). A life-course analysis of military service in Vietnam. Journal of Research in Crime and Delinquency, 42(1), 55-83.

Zoroya, G. (2012, August 16). Army suicide rate hits record in July. The Voice of Tucson. Retrieved from http://tucsoncitizen.com/usa-today-news/2012/08/16/army-suicide-ratehits-record-in-july/ 


\section{APPENDIX A}

Rob Ulrey is an Army veteran, federal law enforcement officer, fledgling blogger, media critic and writer. Interviewed by NBC following publicization of the below post, he shares his thoughts on living with PTSD. He hopes that his experience may help educate the public and address media misinformation. Reproduced with permission.

\section{I have PTSD...So what?}

I have PTSD. We all know what it is, Post Traumatic Stress Disorder. I am one of millions who are affected by it each and every day. Millions of men and women who have varying symptoms yet manage to maintain a normal lifestyle. I, along with my cohorts, have been classified as a potential powder keg just waiting on that spark to set us off into a murderous explosion of ire. This is not the case as I am just as normal as you.

At the end of every day I lay my head down in an attempt to sleep. That in itself is no different than you. But when my eyes close and I should be drifting off into a peaceful bliss, my mind takes over and I am tormented in my dreams with a vivid and exaggerated version of every combat encounter witnessed. There has been nary a night that I do not have this, and have not had an uninterrupted night of sleep for years. Yet in the morning, I rise with the consistency of the sun, roll out of my sweat soaked bed, and shake off the remnants of the nightly battles and start my day...just like you.

I am functional in society, but I am a little more vigilant than you, always on the look-out for danger, avoiding large crowds and loud places. But somehow, I can still manage to go out to eat, shop for my clothes and drive my car. I pay close attention to those around me, see the drug deal that just took place on my right and notice the people who just don't belong in a certain situation. You may not have evil intentions, but I will notice nonetheless.

I have guns. As a matter of fact I just about always have one on me. You see, even though I have PTSD, I am still a Sheepdog watching out for my flock. I don't brandish my weapon and most of the time you won't even know I have it on my body, but it is there. I also carry a large knife in my pocket, one that could cause serious injury or death if used improperly. I have never used any of my weapons in a malicious manner and never will, but in my duties as a Sheepdog I will not hesitate to draw down on you should the circumstance warrant it. I am armed, but I am not dangerous. 
There are times that I am medicated. My PTSD comes in cycles and when things get bad I need that extra chemical push to regulate me. I accept this and because of it I do not drink. I have other physical problems that could easily warrant an addiction to pain killers, but just like most of us with PTSD, I avoid it.

I have never committed violence in the workplace, just like the vast majority of those who suffer with me. My co-workers know I spent time in the military but they do not know of my daily struggles, and they won't. I can still communicate with my subordinates and supervisors in a clear manner. I have never physically assaulted anyone out of anger or rage.

It pains me when I listen to the news and every time a veteran commits a crime (or commits suicide); it is automatically linked to and blamed on PTSD. Yes, there are some who cannot control their actions due to this imbalance in our heads, but don't put a label on us that we are all incorrigible. Very few of us are bad. There are more of us out there that are trying harder to do good than the lesser alternative.

Do not pity me. I know who I am and recognize the journey that has shaped me into what I am. I have no regrets about anything that I have done in the past and look forward to many wonderful years in the future. I freely take every step of life during the day knowing that there is something that will haunt me at night.

For those who are like me, there is help. Seek it out. You were strong enough to make it this far, don't give up. Dig a little deeper and make that final push. If you do not know where to go or have fallen astray, contact me. I will help. We are all brothers and sisters in this battle that will rage invariably for eternity and the one constant is that we have each other.

To the rest of society and particularly the media: I have PTSD!

By "RU Rob"

February 5, 2012

Available at http://rhinoden.rangerup.com/i-have-ptsd-so-what/ 